\title{
Heavy P-Type Carbon Doping of MOCVD GaAsP Using $\mathrm{CBrCl}_{3}$
}

\author{
Christopher Heidelberger ${ }^{1}$ and Eugene A. Fitzgerald \\ Department of Materials Science and Engineering, Massachusetts Institute of \\ Technology, Cambridge, MA 02139, USA \\ ${ }^{1}$ Corresponding Author: Phone: 617-253-6903, Email: chrish@mit.edu
}

\begin{abstract}
$\mathrm{CBrCl}_{3}$ is shown to be a useful precursor for heavy p-type carbon doping of $\mathrm{GaAs}_{\mathrm{x}} \mathrm{P}_{1-\mathrm{x}}$ grown via metalorganic chemical vapor deposition (MOCVD) across a range of compositions. Structural and electrical properties of the GaAsP films were measured for various processing conditions. Use of $\mathrm{CBrCl}_{3}$ decreased the growth rate of GaAsP by up to $32 \%$ and decreases $x$ by up to 0.025 . The dependence of these effects on precursor inputs is investigated, allowing Cdoped GaAsP films to be grown with good thickness and compositional control. Hole concentrations of greater than $2 \times 10^{19} \mathrm{~cm}^{-3}$ were measured for values of $x$ from 0.76 to 0.90 .
\end{abstract}

Keywords: A1. Doping, A3. Metalorganic chemical vapor deposition, B1. Gallium arsenide phosphide, B2. Semiconducting III-V materials

\section{Introduction}

$\mathrm{GaAs}_{\mathrm{x}} \mathrm{P}_{1-\mathrm{x}}$ is a ternary III-V semiconductor which has found many uses. Since the early 1970s, it has been widely used to fabricate red, orange, and yellow light emitting diodes [1,2]. It was studied for use as a graded base layer in heterojunction bipolar transistors (HBTs) in the 1990s [3]. More recently, GaAsP has become a material of interest for the high-bandgap cell in multi-junction photovoltaic systems [4-6]. For III-V on Si applications, it is useful because it is 
a miscible alloy and nearly bridges the entire gap in lattice constant between Si and GaAs. Metalorganic chemical vapor deposition (MOCVD) has been the method of choice for most commercial growth of GaAsP and other III-V semiconductors.

Heavy p-type doping of GaAsP in excess of $1 \times 10^{19} \mathrm{~cm}^{-3}$ is required in several device elements, such as Ohmic contact layers, tunnel junctions, and the base regions of HBTs. Carbon has an advantage over group II p-type dopants in its lower diffusivity [7] and higher solid solubility in GaAs [8]. There are several ways of doping with C in MOCVD. Various hydrocarbon sources have been used, including the methyl group from TMGa, but these generally require low growth temperatures and/or low V/III ratios and therefore result in a high density of deep-level traps and bad surface morphology $[9,10]$.

$\mathrm{CBrCl}_{3}$ and other halomethanes allow higher growth temperatures and $\mathrm{V} / \mathrm{III}$ ratios so highquality C-doped films can be grown [11]. However, they create reactive byproducts which can have two adverse effects on $\mathrm{GaAs}_{\mathrm{x}} \mathrm{P}_{1-\mathrm{x}}$ growth: substantial growth rate reduction [12] and composition shift (change in $x$ ) [13]. Control over growth rate and composition is critical for device fabrication; therefore, it is important that we are able to understand the effect of $\mathrm{C}$ doping by $\mathrm{CBrCl}_{3}$ on these parameters. In this paper, we report the thicknesses, compositions, and electrical properties of various C-doped GaAsP films.

\section{Experiments}

The epitaxial samples were prepared in a Thomas Swan/Aixtron cold-walled 6x2" MOCVD reactor, with a close-coupled showerhead configuration. Trimethylgallium (TMGa) was used as a Ga precursor and $\mathrm{AsH}_{3}$ and $\mathrm{PH}_{3}$ were used as group V precursors. In the $1980 \mathrm{~s}, \mathrm{CCl}_{4}$ was originally used as a $\mathrm{C}$ precursor for MOCVD GaAs [11], but is now unavailable for 
environmental reasons. Replacing one or more $\mathrm{Cl}$ atoms with $\mathrm{Br}$ yields compounds which are potential candidates; however, of these only $\mathrm{CBrCl}_{3}$ is a liquid at room temperature, an important criterion for bubbler design. Hence, in this study $\mathrm{CBrCl}_{3}$ was used as a $\mathrm{C}$ precursor, with a bubbler temperature of $26^{\circ} \mathrm{C}$. The total reactor pressure for all samples was 100 Torr, with $\mathrm{N}_{2}$ used as carrier gas. Susceptor rotation speed was $100 \mathrm{rpm}$.

Samples were grown with a structure shown in Figure 1. Si substrates were used for all GaAsP samples because tensile GaAsP films grown on GaAs substrates had a tendency to crack, yielding inaccurate Hall effect measurements. N-type (100) Si substrates with a $6^{\circ}$ offcut were used. The offcut is necessary to obtain single-domain $\mathrm{GaAsP}$ [14]. $\mathrm{Si}_{0.5} \mathrm{Ge}_{0.5}$ was grown via a $\mathrm{Si}_{1-\mathrm{y}} \mathrm{Ge}_{\mathrm{y}}$ graded buffer using a vertical-tube UHVCVD reactor. The wafers were then chemicalmechanically polished to remove surface roughness [15]. Next, in the MOCVD reactor, a $\mathrm{Si}_{1-}$ ${ }_{y} \mathrm{Ge}_{\mathrm{y}}$ graded buffer was grown from $\mathrm{y}=0.5$ to $\mathrm{y}=0.75$, upon which an $\mathrm{n}$-type $\mathrm{GaAs}_{0.74} \mathrm{P}_{0.26}$ film was initiated at $725^{\circ} \mathrm{C}$ and grown to $500 \mathrm{~nm}$. Then, under a mixed $\mathrm{AsH}_{3}$ and $\mathrm{PH}_{3}$ overpressure, the growth temperature was lowered to the final growth temperature $\left(600{ }^{\circ} \mathrm{C}\right.$ or $\left.650{ }^{\circ} \mathrm{C}\right)$. A Cdoped GaAsP film was then deposited for $1000 \mathrm{~s}$ with a TMGa flow of $132 \mu \mathrm{mol} / \mathrm{min}$ and a V/III ratio of about 100. The $\mathrm{C}$-doped GaAs and GaP films were grown directly on their respective $\mathrm{n}$ type substrates rather than on $\mathrm{Si}$.

Table 1 shows a summary of the process conditions for all of the C-doped GaAsP films, grown at a variety of temperatures, $\mathrm{CBrCl}_{3}$ flow rates, and $\mathrm{AsH}_{3}$ fractions. $\mathrm{AsH}_{3}$ fraction, the chosen metric of As precursor in the gas phase, is defined as:

$\mathrm{AsH}_{3}$ Fraction $=\frac{P_{\mathrm{AsH}_{3}}}{P_{\mathrm{AsH}_{3}}+P_{\mathrm{PH}_{3}}}$,

where $P_{\mathrm{AsH}_{3}}$ and $P_{\mathrm{PH}_{3}}$ are the input partial pressures of $\mathrm{AsH}_{3}$ and $\mathrm{PH}_{3}$, respectively. 
Sample A was grown at a temperature of $650{ }^{\circ} \mathrm{C}$, while all other samples were grown at 600 ${ }^{\circ} \mathrm{C}$. Samples B-F vary $\mathrm{AsH}_{3}$ fraction, and therefore the solid $\mathrm{GaAs}_{\mathrm{x}} \mathrm{P}_{1-\mathrm{x}}$ composition, while keeping a constant $\mathrm{CBrCl}_{3}$ flow. Samples $\mathrm{G}, \mathrm{C}$, and $\mathrm{H}$ vary the $\mathrm{CBrCl}_{3}$ flow with a constant $\mathrm{AsH}_{3}$ fraction. Sample $\mathrm{J}$ has multiple GaAsP layers with varying $\mathrm{AsH}_{3}$ fractions and no $\mathrm{CBrCl}_{3}$ flow. The $\mathrm{AsH}_{3}$ fractions of $0.18-0.37$ were chosen because at a growth temperature of $600{ }^{\circ} \mathrm{C}$, they result in GaAsP compositions which span most of the direct band gap range [16]. The V/III ratio was kept constant while varying $\mathrm{AsH}_{3}$ fraction.

Layer thicknesses were measured using cross-sectional SEM. High-resolution x-ray diffraction was used to measure film composition. (004) and (224) reciprocal space maps of the film and substrate were collected and used to find the in-plane and out-of-plane lattice constants of the C-doped GaAsP film using the methodology described in detail in Section 3.1 of Roesener et al. [17]. These values allowed for estimation of the relaxed lattice constant, using a Poisson ratio interpolated from the $\mathrm{GaP}$ and $\mathrm{GaAs}$ endpoints. The As content of the film was then calculated by Vegard's law. Hall effect measurements used the van der Pauw geometry and a permanent magnet with a field of $0.412 \mathrm{~T}$. Indium was used to make contact to the GaAsP film. Given the finite size of the contacts, an error in Hall effect voltage of 5\% was estimated [18]. Because of the pronounced effect of $\mathrm{CBrCl}_{3}$ on $\mathrm{GaAsP}$ growth rate, the individually measured thickness of each sample was used in calculating its bulk carrier concentration. Leakage current into the n-type buffer layers and substrate was measured for representative Hall effect structures. Reverse bias leakage current from the p-doped GaAsP film into the n-doped substrate was less than $0.1 \%$ of the current between two Hall effect terminals at the same voltage. Therefore, any contribution of the n-type substrate to the sheet resistance or Hall voltage measurements was 
deemed to be insignificant. C concentration in Sample H was measured using secondary ion mass spectrometry (SIMS).

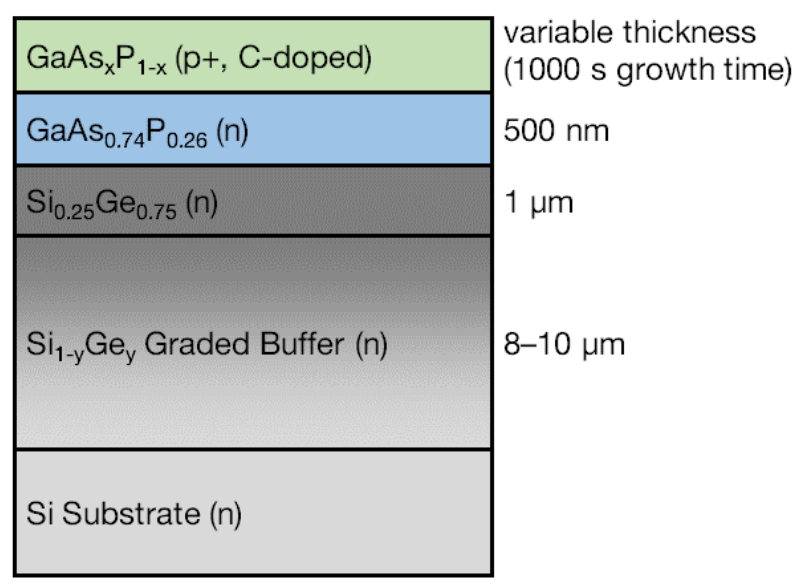

Figure 1: Cross-sectional schematic of the epitaxial samples.

\begin{tabular}{llll}
\hline Sample ID & Temperature $\left({ }^{\circ} \mathrm{C}\right)$ & $\mathrm{CBrCl}_{3}$ Flow $(\mu \mathrm{mol} / \mathrm{min})$ & $\mathrm{AsH}_{3}$ Fraction \\
\hline $\mathrm{A}$ & 650 & 118 & 0.53 \\
$\mathrm{~B}$ & 600 & 59 & 0 \\
$\mathrm{C}$ & 600 & 59 & 0.18 \\
$\mathrm{D}$ & 600 & 59 & 0.27 \\
$\mathrm{E}$ & 600 & 59 & 0.37 \\
$\mathrm{~F}$ & 600 & 59 & 1 \\
$\mathrm{G}$ & 600 & 15 & 0.18 \\
$\mathrm{H}$ & 600 & 118 & 0.18 \\
$\mathrm{~J}$ & 600 & 0 & $0.18,0.27,0.37$ \\
\hline
\end{tabular}

Table 1: List of GaAsP samples with growth conditions.

\section{Results and Discussion}

\subsection{Effect of Growth Temperature}

Sample A, grown at $650{ }^{\circ} \mathrm{C}$, yielded a hole concentration of $9 \times 10^{17} \mathrm{~cm}^{-3}$. This is too low for the applications discussed in Section 1. Growth temperatures of $650{ }^{\circ} \mathrm{C}$ and higher are 
preferred for MOCVD growth of GaAsP. This is due to increased concentrations of impurities at lower temperatures as well as decreased $\mathrm{PH}_{3}$ cracking efficiency $[19,20]$. However, it is known that a decreased growth temperature of $600{ }^{\circ} \mathrm{C}$ or lower produces the highest hole concentrations in C-doped GaAs [11,12]. Sample H, grown with the same $\mathrm{CBrCl}_{3}$ flow rate as Sample A but at $600{ }^{\circ} \mathrm{C}$, yielded a hole concentration of $2 \times 10^{19} \mathrm{~cm}^{-3}$. This confirms that the active $\mathrm{C}$ doping of GaAsP also increases with decreasing growth temperature. The rest of this study focuses on a growth temperature of $600{ }^{\circ} \mathrm{C}$ because growth temperatures less than $600{ }^{\circ} \mathrm{C}$ are undesirable for the reasons mentioned above.

\subsection{Growth Rate Reduction by $\mathrm{CBrCl}_{3}$}

The growth rate of GaAsP was decreased by the introduction of $\mathrm{CBrCl}_{3}$. Figure 2 shows the growth rate reduction for a single $\mathrm{AsH}_{3}$ fraction (0.18) as a function of $\mathrm{CBrCl}_{3}$ flow. Lee et al. model the growth rate reduction of $\mathrm{GaAs}$ by $\mathrm{CCl}_{4}$ as:

$r=k_{0}\left[\mathrm{CX}_{4}\right][\mathrm{V} / \mathrm{III}]^{-0.5} \exp \left(-\frac{E_{a}}{k T}\right)$,

where $\left[\mathrm{CX}_{4}\right]$ is the concentration of $\mathrm{C}$ precursor $\left(\mathrm{CCl}_{4}\right.$ in Lee et al.), $E_{a}$ is the activation energy of formation of $\mathrm{GaCl}$ from $\mathrm{Ga}$ and $\mathrm{Cl}$, and $k_{0}$ is a constant dependent on other factors [12]. The proportional dependence on $\mathrm{C}$ precursor concentration agrees with our data for GaAsP, suggesting that the growth rate reduction is caused by reaction of either $\mathrm{Cl}$ or $\mathrm{Br}$ byproducts with Ga or Ga precursor.

Growth rate reduction does not change appreciably with $\mathrm{AsH}_{3}$ fraction at a constant $\mathrm{CBrCl}_{3}$ flow rate, as shown in Figure 3. This is further evidence that the growth rate reduction is limited by the reaction of $\mathrm{Br}$ or $\mathrm{Cl}$ byproducts with $\mathrm{Ga}$, and that group $\mathrm{V}$ species are not involved. 


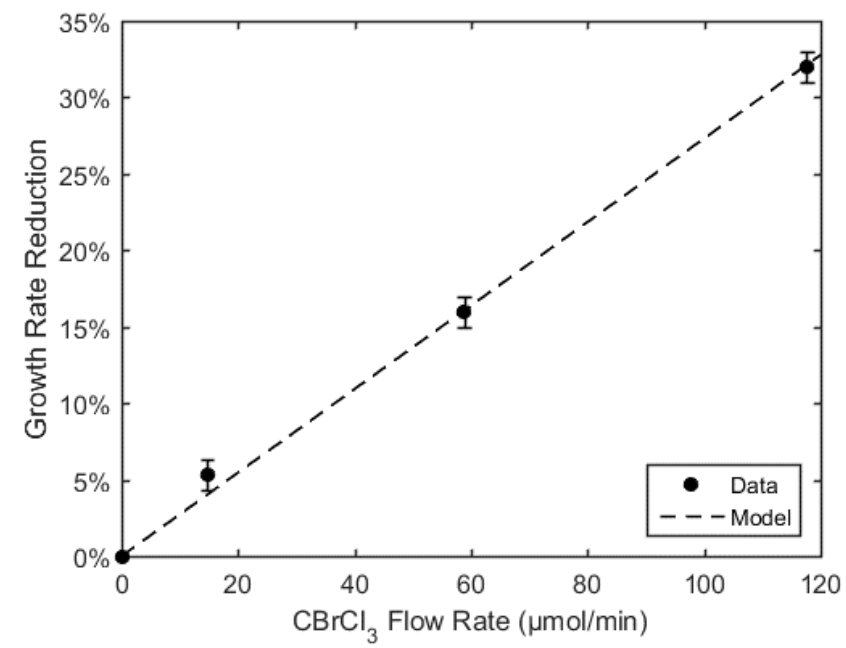

Figure 2: Reduction in GaAsP growth rate as a function of $\mathrm{CBrCl}_{3}$ flow rate.

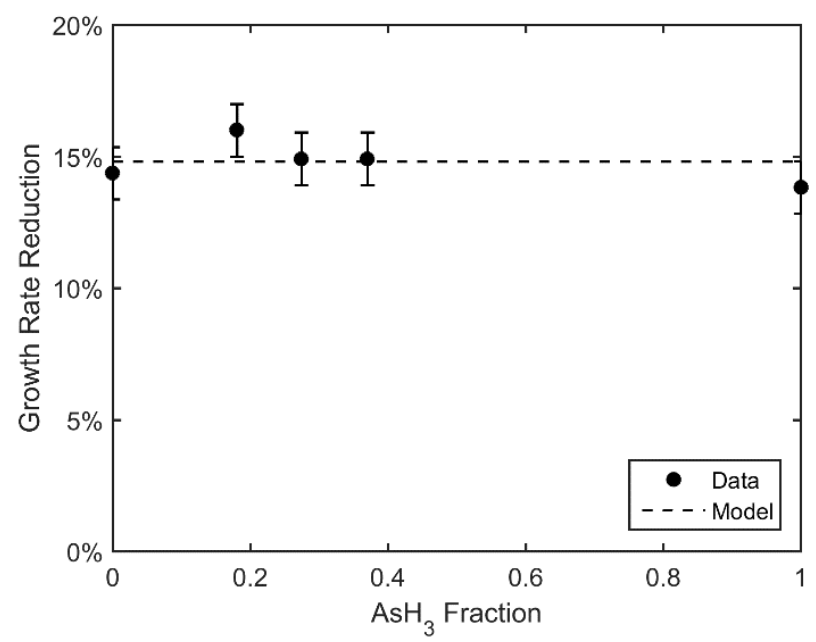

Figure 3: Reduction in GaAsP growth rate as a function of $\mathrm{AsH}_{3}$ fraction.

\section{3 $\operatorname{GaAs}_{\mathrm{x}} \mathbf{P}_{1-\mathrm{x}}$ Composition Shift due to $\mathrm{CBrCl}_{3}$}

Figure 4a shows the $\mathrm{GaAs}_{\mathrm{x}} \mathrm{P}_{1-\mathrm{x}}$ composition $(x)$ with a constant $\mathrm{AsH}_{3}$ fraction of 0.2 and a varying $\mathrm{CBrCl}_{3}$ flow. The introduction of $\mathrm{CBrCl}_{3}$ increases the As fraction in the solid phase $(x)$. This trend was also observed by Tateno et al. for InGaAsP doped by $\mathrm{CBr}_{4}$ [13]. The shift in $x$ is approximately the same for all $\mathrm{CBrCl}_{3}$ flows tested $(15-118 \mu \mathrm{mol} / \mathrm{min})$. 
The incorporation of high amounts of $\mathrm{C}$ is expected to have an effect on the GaAsP lattice constant due to Vegard's Law [21]. However, this shift would be opposite in sign to the shift observed here, that is, towards smaller rather than larger lattice constants. In addition, the magnitude of the shift due to $\mathrm{C}$ incorporation is expected to be a small fraction $(<10 \%)$ of the observed shift, so it is ignored here.

$\operatorname{GaAs}_{\mathrm{x}} \mathrm{P}_{1-\mathrm{x}}$ composition $(x)$ versus $\mathrm{AsH}_{3}$ fraction is shown in Figure $4 \mathrm{~b}$ for both no $\mathrm{CBrCl}_{3}$ and for a $\mathrm{CBrCl}_{3}$ flow of $59 \mu \mathrm{mol} / \mathrm{min}$. Smeets et al. model the relationship between the input partial pressures of $\mathrm{AsH}_{3}$ and $\mathrm{PH}_{3}$ and $x$ as:

$\frac{1-x}{x}=C \frac{P_{\mathrm{PH}_{3}}}{P_{\mathrm{AsH}_{3}}}$

where $C$ is a fitting constant with an Arrhenius dependence and an activation energy close to that of the $\mathrm{PH}_{3}$ cracking energy [22]. For the case of no $\mathrm{CBrCl}_{3}$, this equation fits the data well with $C$ equal to 0.075 . For a $\mathrm{CBrCl}_{3}$ flow of $59 \mu \mathrm{mol} / \mathrm{min}$, the data is well-fit with an adjusted $C$ of 0.066. Equation 3 with both values for $C$ is plotted in Figure $4 \mathrm{~b}$. This modified model suggests that the $\mathrm{CBrCl}_{3}$ is slowing the $\mathrm{PH}_{3}$ cracking or otherwise consuming a certain fraction of $\mathrm{PH}_{3}$, reducing the amount of elemental $\mathrm{P}$ available to enter the film. This could be due to formation of $\mathrm{PCl}_{3}, \mathrm{PBr}_{3}$, or similar species. 


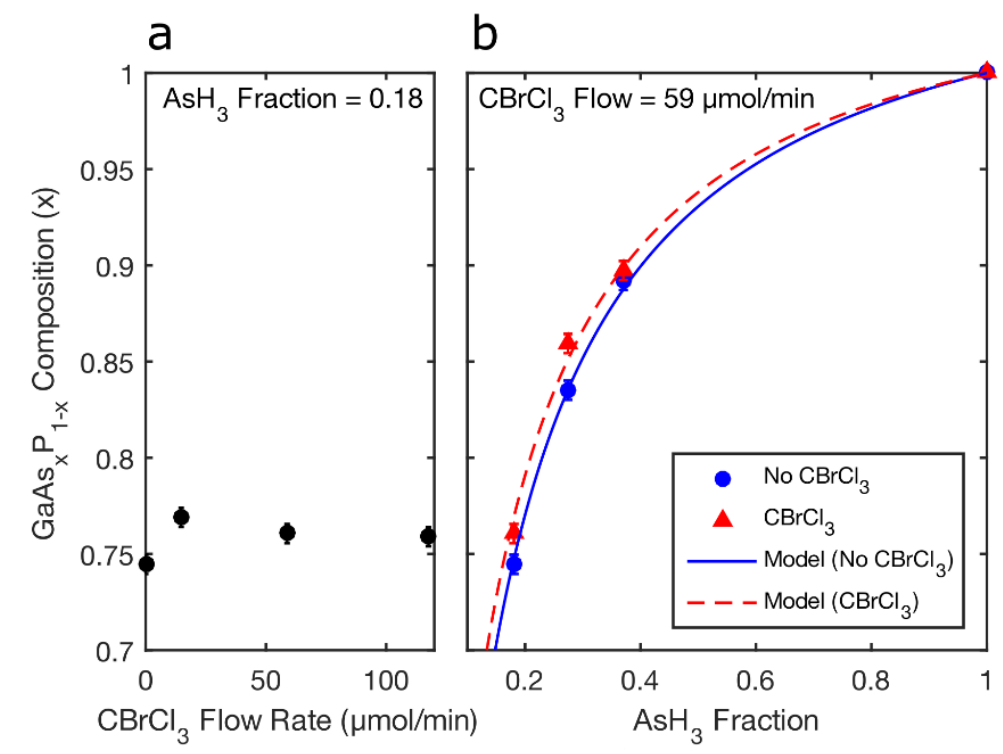

Figure 4: GaAsP composition (As fraction) versus (a) $\mathrm{CBrCl}_{3}$ flow rate and (b) $\mathrm{AsH}_{3}$ fraction.

\subsection{Carrier Concentration and Mobility}

Room-temperature hole concentration and mobility versus $\mathrm{CBrCl}_{3}$ flow rate with a fixed $\mathrm{AsH}_{3}$ fraction (0.18) are shown in Figure 5. A saturation of hole concentration at $2 \times 10^{19} \mathrm{~cm}^{-3}$ is observed at high $\mathrm{CBrCl}_{3}$ flow rates. The $\mathrm{C}$ concentration of Sample $\mathrm{H}\left(\mathrm{AsH}_{3}\right.$ fraction of 0.18 and $\mathrm{CBrCl}_{3}$ flow rate of $118 \mu \mathrm{mol} / \mathrm{min}$ ) was measured by SIMS to be $4 \times 10^{19} \mathrm{~cm}^{-3} \pm 1 \times 10^{19}$ $\mathrm{cm}^{-3}$, corresponding to a dopant activation near $50 \%$. The error in $\mathrm{C}$ concentration is large because of the unknown matrix effects of GaAsP compared to available GaAs standards. The dopant activation level of near 50\% suggests that the saturation in hole concentration is due to a combination of multiple factors: a limitation in incorporation of $\mathrm{C}$ into the GaAsP film along with a reduction in dopant activation.

Figure 6 shows the room-temperature hole concentration and mobility as a function of $\mathrm{AsH}_{3}$ fraction with a constant $\mathrm{CBrCl}_{3}$ flow rate of $59 \mu \mathrm{mol} / \mathrm{min}$. Hole concentrations for the three GaAsP samples are similar, while that of the GaAs and GaP samples are lower. Hole mobility increases almost linearly with increasing $\mathrm{AsH}_{3}$ fraction. This behavior could be due to a 
decrease in hole effective mass with increasing As concentration in combination with changing amounts of dopant scattering from incorporated $\mathrm{C}$.

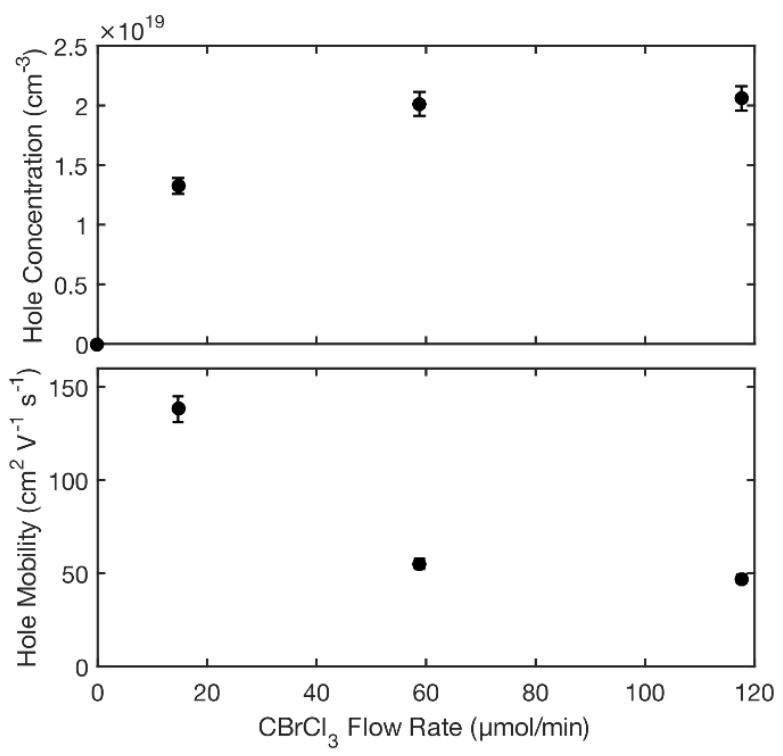

Figure 5: Hole concentration and mobility versus $\mathrm{CBrCl}_{3}$ flow rate with a fixed $\mathrm{AsH}_{3}$ fraction (0.18).

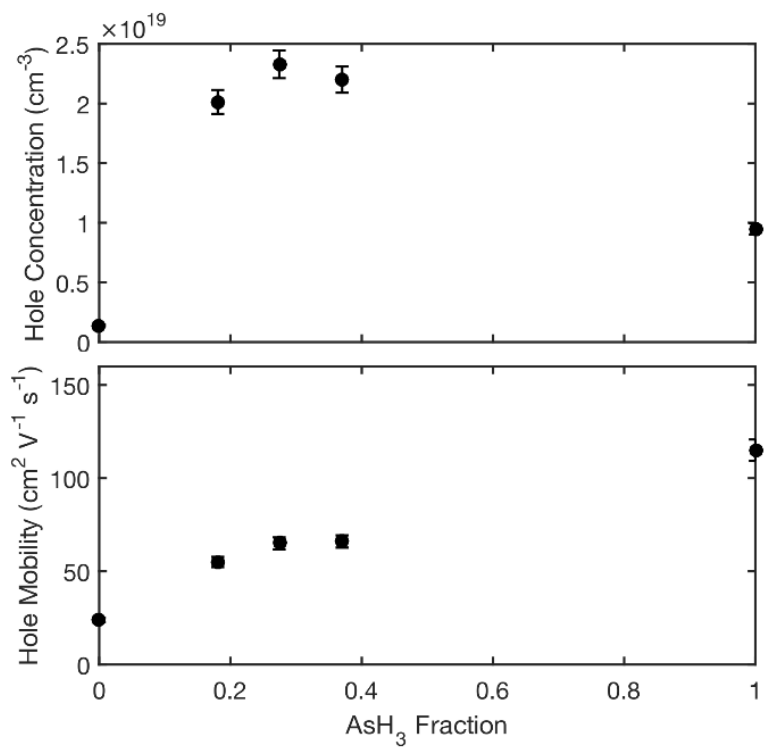

Figure 6: Hole concentration and mobility versus $\mathrm{AsH}_{3}$ fraction with a fixed $\mathrm{CBrCl}_{3}$ flow rate (50 $\left.\mu \mathrm{mol} / \mathrm{min}\right)$. 


\section{Conclusions}

We found that $\mathrm{CBrCl}_{3}$ can be used to grow GaAsP at a range of compositions with heavy ptype doping via MOCVD. The growth rate reduction of $\mathrm{GaAsP}$ due to $\mathrm{CBrCl}_{3}$ was found to be proportional to $\mathrm{CBrCl}_{3}$ flow rate and constant across $\mathrm{GaAsP}$ composition. This suggests that like for $\mathrm{GaAs}$, the growth rate reduction is caused by the formation of $\mathrm{GaCl}$ or $\mathrm{GaBr}$. GaAsP composition shifts towards $\mathrm{GaAs}$ due to $\mathrm{CBrCl}_{3}$, and was modeled using an adjusted equation from Smeets et al. By accounting for the growth rate and composition shifts, C-doped GaAsP films can be grown with the required precision. Hole concentrations of greater than $2 \times 10^{19} \mathrm{~cm}^{-3}$ were achieved across a range of compositions with a $\mathrm{CBrCl}_{3}$ flow rate of 59 $\mu \mathrm{mol} / \mathrm{min}$. At higher $\mathrm{CBrCl}_{3}$ flows, the hole concentration saturated. Hole mobility increased linearly with increasing $\mathrm{AsH}_{3}$ fraction.

\section{Acknowledgements}

This work was supported by the Center for Energy Efficient Electronics Science (NSF Award 0939514). This work was also supported by a research grant from the Singapore-MIT Alliance for Research and Technology Low Energy Electronic Systems Program, a program funded by the National Research Foundation of Singapore. This work made use of the MRSEC Shared Experimental Facilities at MIT, supported by NSF Award DMR-14-19807.

\section{References}

[1] A. Bergh, P.J. Dean, Light-emitting diodes, Proc. IEEE. 60 (1972) 156-223.

[2] M.G. Craford, W.O. Groves, Vapor Phase Epitaxial Materials for LED Applications, Proc. IEEE. 61 (1973) 862-880.

[3] M. Ohkubo, N. Ikeda, T. Ninomiya, Graded-GaAs1-xPx base in heterojunction bipolar transistors with InGaP emitters, in: Indium Phosphide Relat. Mater., 1995: pp. 456-459.

[4] T.J. Grassman, M.R. Brenner, M. Gonzalez, A.M. Carlin, R.R. Unocic, R.R. Dehoff, et 
al., Characterization of metamorphic GaAsP/Si materials and devices for photovoltaic applications, IEEE Trans. Electron Devices. 57 (2010) 3361-3369.

doi:10.1109/TED.2010.2082310.

[5] K.N. Yaung, J.R. Lang, M.L. Lee, N. Haven, Towards high efficiency GaAsP solar cells on (001) GaP/Si, in: Photovolt. Spec. Conf. (PVSC), 2014 IEEE 40th, 2014: pp. 831-835. doi:10.1109/PVSC.2014.6925043.

[6] T. Milakovich, R. Shah, S. Hadi, M. Bulsara, A. Nayfeh, Growth and characterization of GaAsP top cells for high efficiency III-V / Si tandem PV, in: Photovolt. Spec. Conf. (PVSC), 2015 IEEE 42nd, 2015: pp. 1-4. doi:10.1109/PVSC.2015.7355598.

[7] B.T. Cunningham, L.J. Guido, J.E. Baker, J.S.M. Jr., N.H. Jr., G.E. Stillman, Carbon diffusion in undoped, n-type, and p-type GaAs, Appl. Phys. Lett. 55 (1989) 687-689. doi:10.1063/1.101822.

[8] M. Konagai, T. Yamada, T. Akatsuka, K. Saito, E. Tokumitsu, K. Takahashi, Metallic ptype GaAs and GaAlAs grown by metalorganic molecular beam epitaxy, J. Cryst. Growth. 98 (1989) 167-173.

[9] H. Zhu, Y. Adachi, T. Ikoma, Deep levels in MOCVD GaAs grown under different Ga/As mol fractions, J. Cryst. Growth. 55 (1981) 154-163.

[10] M. Kushibe, K. Eguchi, M. Funamizu, Y. Ohba, Heavy carbon doping in metalorganic chemical vapor deposition for GaAs using a low V/III ratio, Appl. Phys. Lett. 56 (1990) 1248. doi:10.1063/1.103181.

[11] B.T. Cunningham, M.A. Haase, M.J. McCollum, J.E. Baker, G.E. Stillman, Heavy carbon doping of metalorganic chemical vapor deposition grown GaAs using carbon tetrachloride, Appl. Phys. Lett. 54 (1989) 1905-1907. doi:10.1063/1.101237.

[12] J.-S. Lee, I. Kim, B.-D. Choe, W.G. Jeong, Carbon doping and growth rate reduction by CCl4 during metalorganic chemical-vapor deposition of GaAs, J. Appl. Phys. 76 (1994) 5079-5084. doi:10.1063/1.357219.

[13] K. Tateno, C. Amano, Carbon doping and etching in GaxIn1-xAsyP1-y on GaAs substrates using $\mathrm{CBr} 4$ by metalorganic chemical vapor deposition, J. Electron. Mater. 28 (1999) 63-68. doi:10.1007/s11664-999-0196-6.

[14] Y. Bolkhovityanov, O. Pchelyakov, GaAs epitaxy on Si substrates: modern status of research and engineering, Physics-Uspekhi. 51 (2008) 437-456. doi:10.3367/UFNr.0178.200805b.0459.

[15] M.T. Currie, S.B. Samavedam, T.A. Langdo, C.W. Leitz, E.A. Fitzgerald, Controlling threading dislocation densities in Ge on Si using graded SiGe layers and chemicalmechanical polishing, Appl. Phys. Lett. 72 (1998) 1718-1720. doi:10.1063/1.121162.

[16] I. Vurgaftman, J.R. Meyer, L.R. Ram-Mohan, Band parameters for III-V compound semiconductors and their alloys, J. Appl. Phys. 89 (2001) 5815. doi:10.1063/1.1368156. 
[17] T. Roesener, V. Klinger, C. Weuffen, D. Lackner, F. Dimroth, Determination of heteroepitaxial layer relaxation at growth temperature from room temperature X-ray reciprocal space maps, J. Cryst. Growth. 368 (2013) 21-28.

doi:10.1016/j.jcrysgro.2013.01.007.

[18] R. Chwang, B.J. Smith, C.R. Crowell, Contact Size Effects on the Van Der Pauw Method for Resistivity and Hall Coefficient Measurement, Solid. State. Electron. 17 (1974) 12171227. doi:10.1016/0038-1101(74)90001-X.

[19] M. Kondo, T. Tanahashi, Dependence of carbon incorporation on crystallographic orientation during metalorganic vapor phase epitaxy of GaAs and AlGaAs, J. Cryst. Growth. 145 (1994) 390-396. doi:10.1016/0022-0248(94)91081-2.

[20] C.A. Larsen, N.I. Buchan, G.B. Stringfellow, Mass spectrometric studies of phosphine pyrolysis and OMVPE growth of InP, J. Cryst. Growth. 85 (1987) 148-153.

[21] M.C. Hanna, Z.H. Lu, A. Majerfeld, Very high carbon incorporation in metalorganic vapor phase epitaxy of heavily doped p-type GaAs, Appl. Phys. Lett. 58 (1991) 164-166. doi:10.1063/1.104960.

[22] E.T.J.M. Smeets, Solid Composition of GaAs1-xPx Grown by Organometallic Vapour Phase Epitaxy, J. Cryst. Growth. 82 (1987) 385-395. 
$\mathrm{GaAs}_{\mathrm{x}} \mathrm{P}_{1-\mathrm{x}}(\mathrm{p}+, \mathrm{C}-\mathrm{doped})$

$\mathrm{GaAs}_{0.74} \mathrm{P}_{0.26}(\mathrm{n})$

$\mathrm{Si}_{0.25} \mathrm{Ge}_{0.75}(\mathrm{n})$

$\mathrm{Si}_{1-y} \mathrm{Ge}_{\mathrm{y}}$ Graded Buffer (n)

Si Substrate (n) variable (1000 s growth)

$500 \mathrm{~nm}$

$1 \mu \mathrm{m}$

8-10 $\mu \mathrm{m}$ 


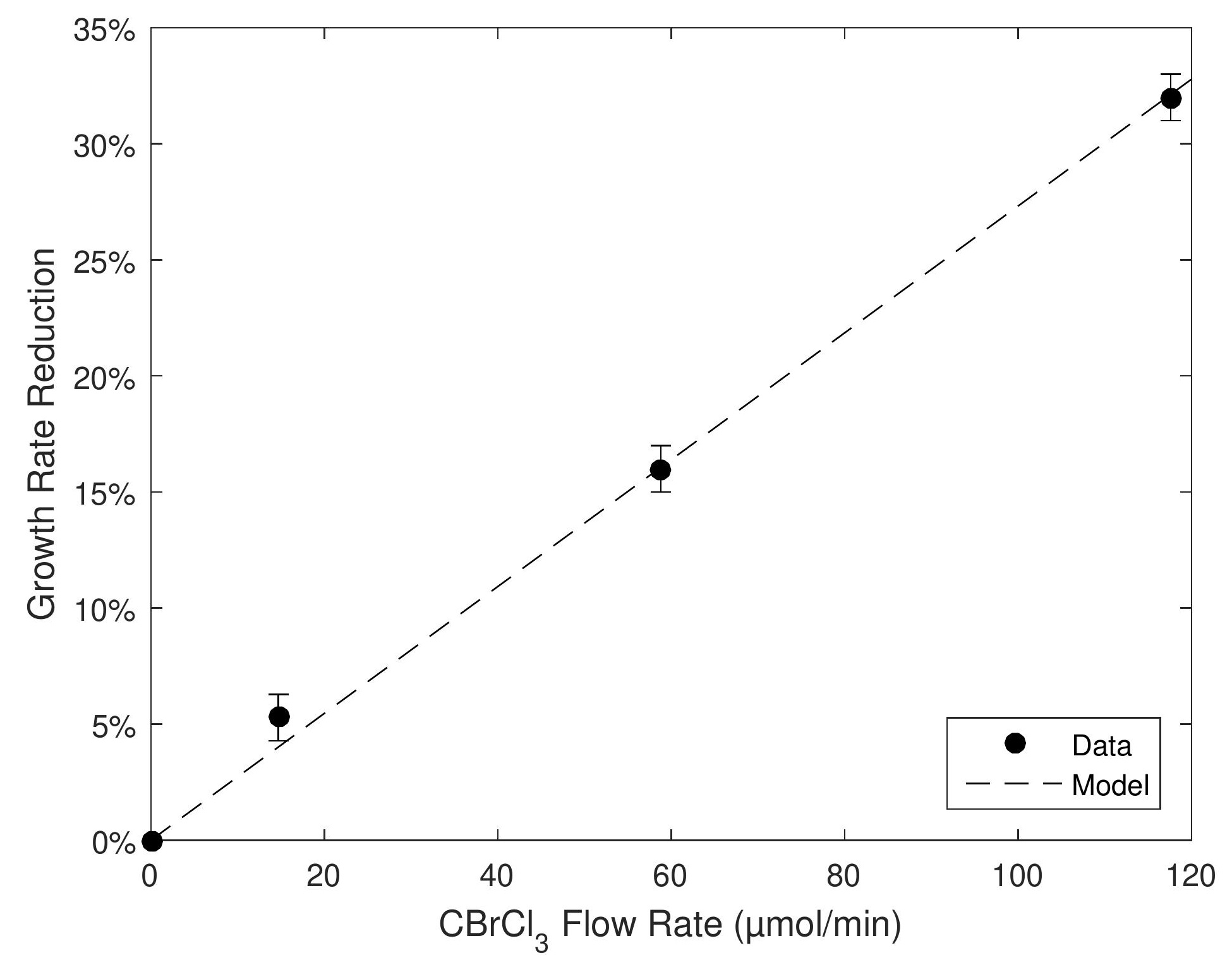

Figure 2 
Figure 3

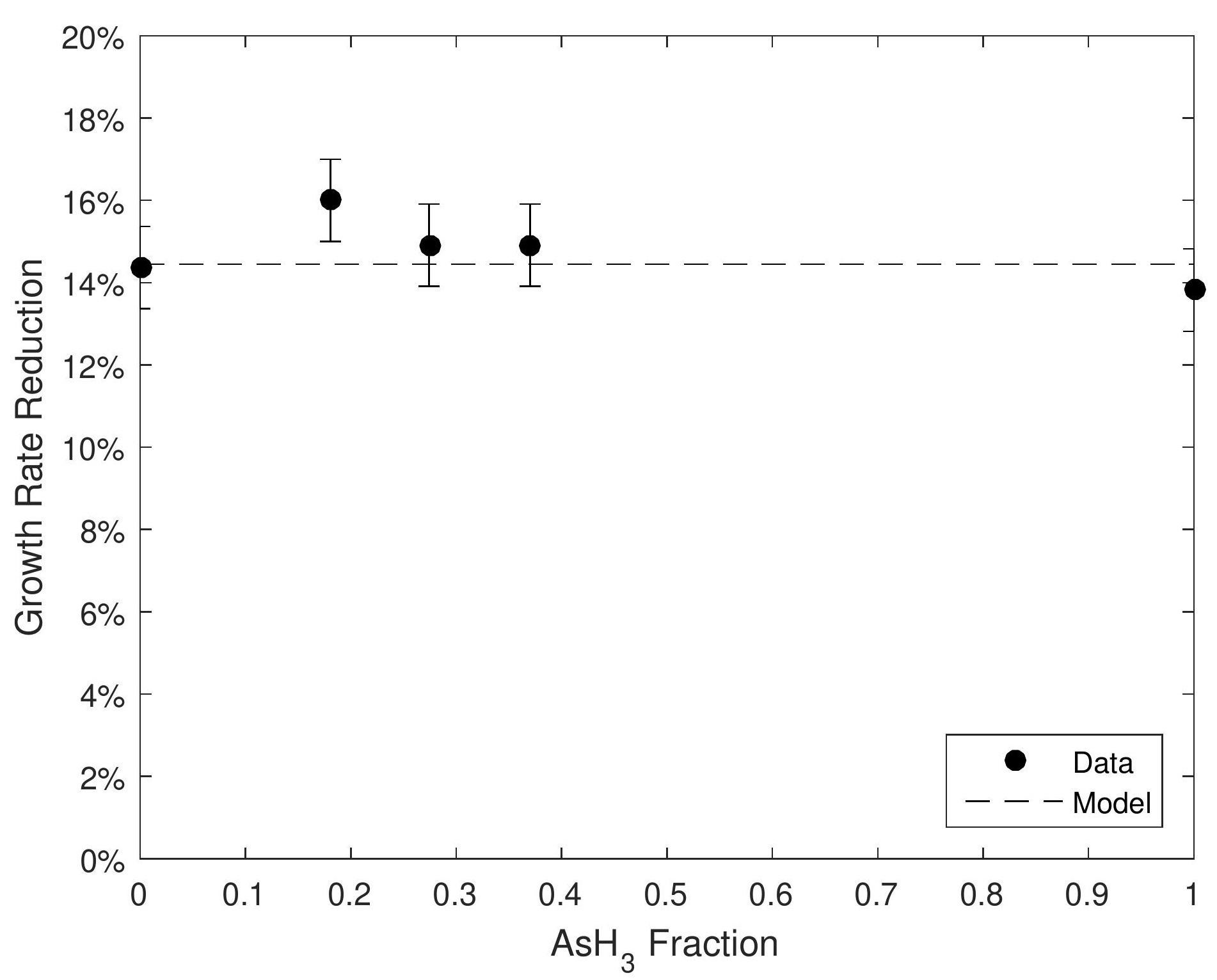




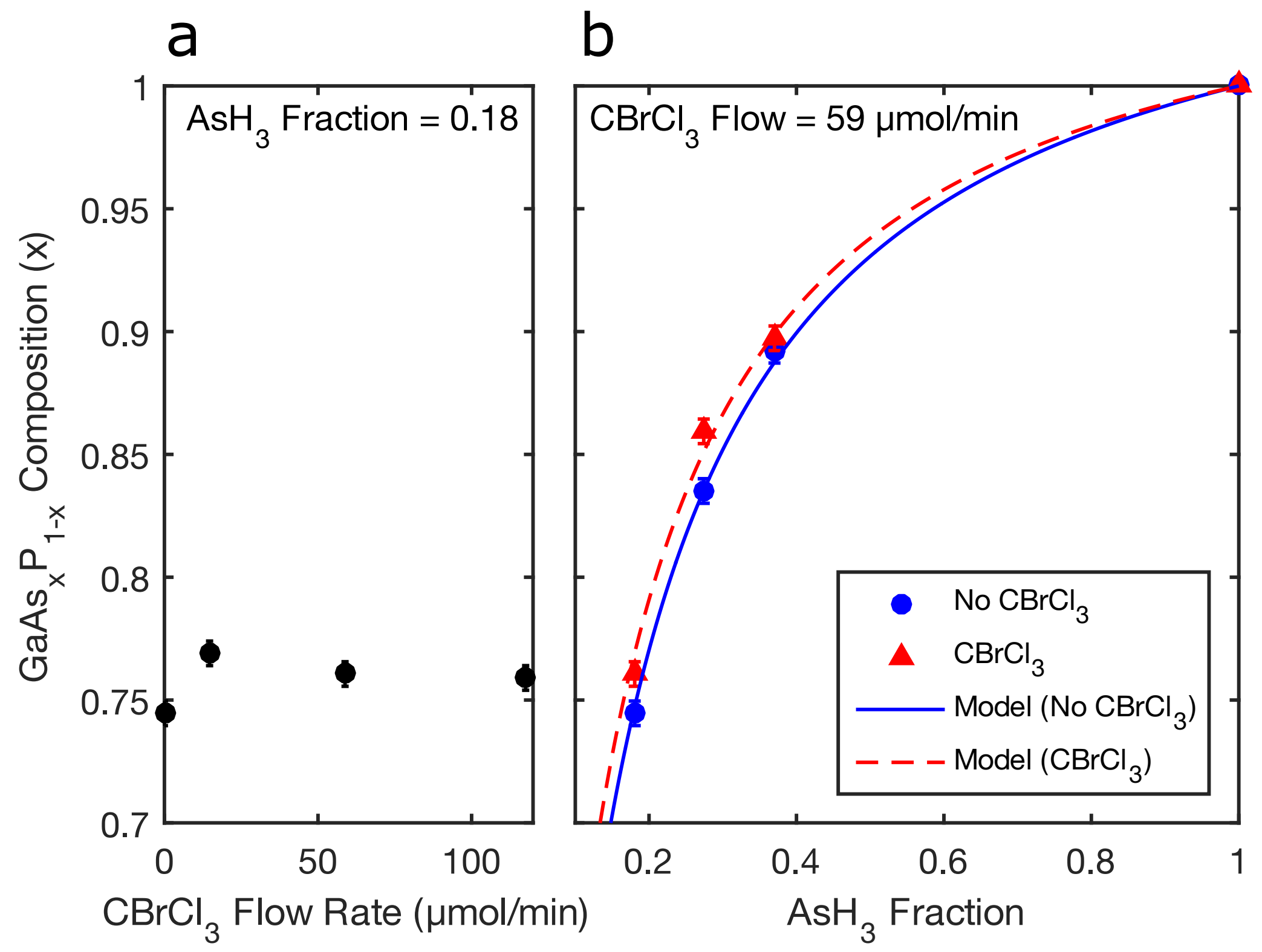


Figure 5

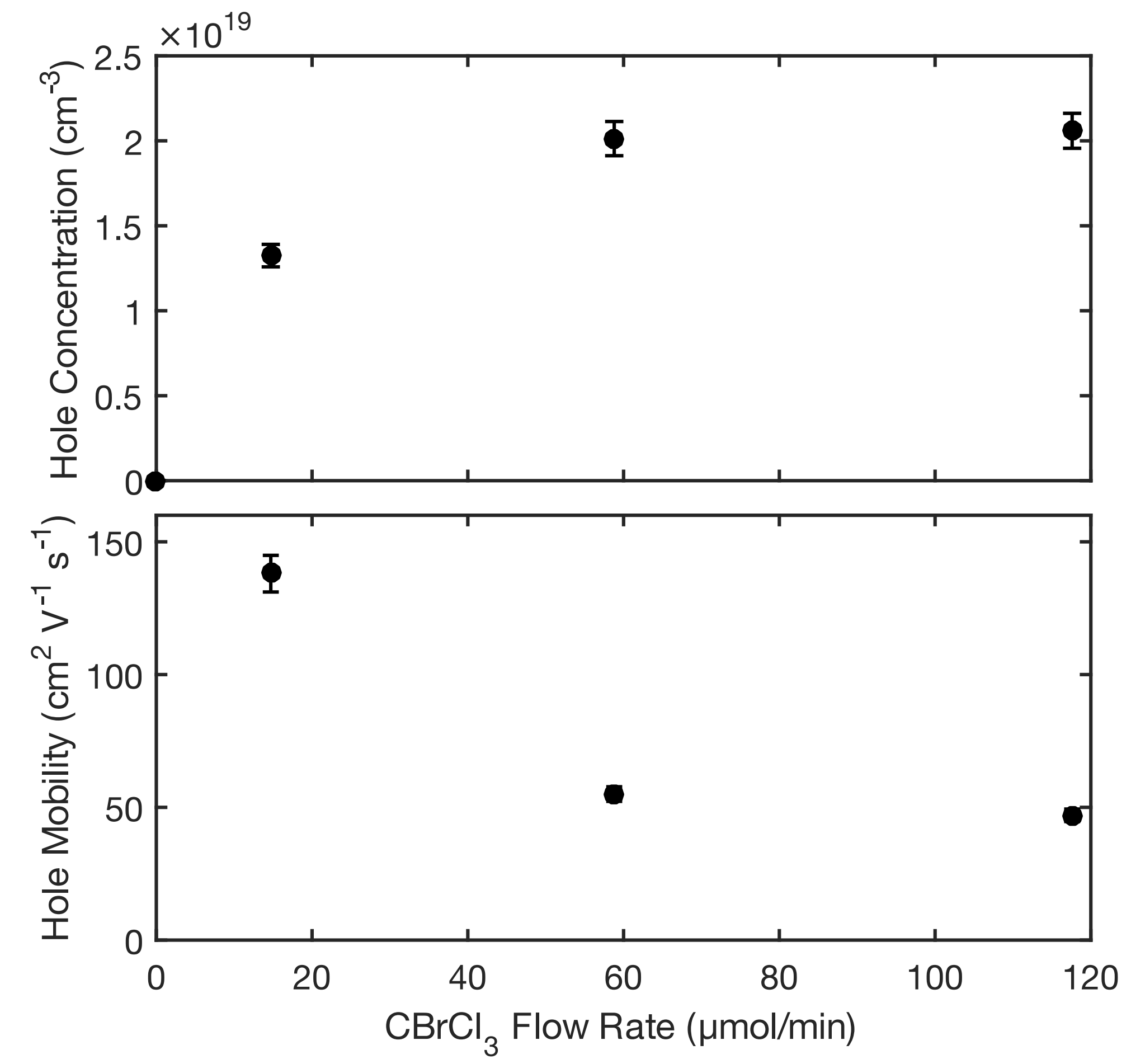


Figure 6

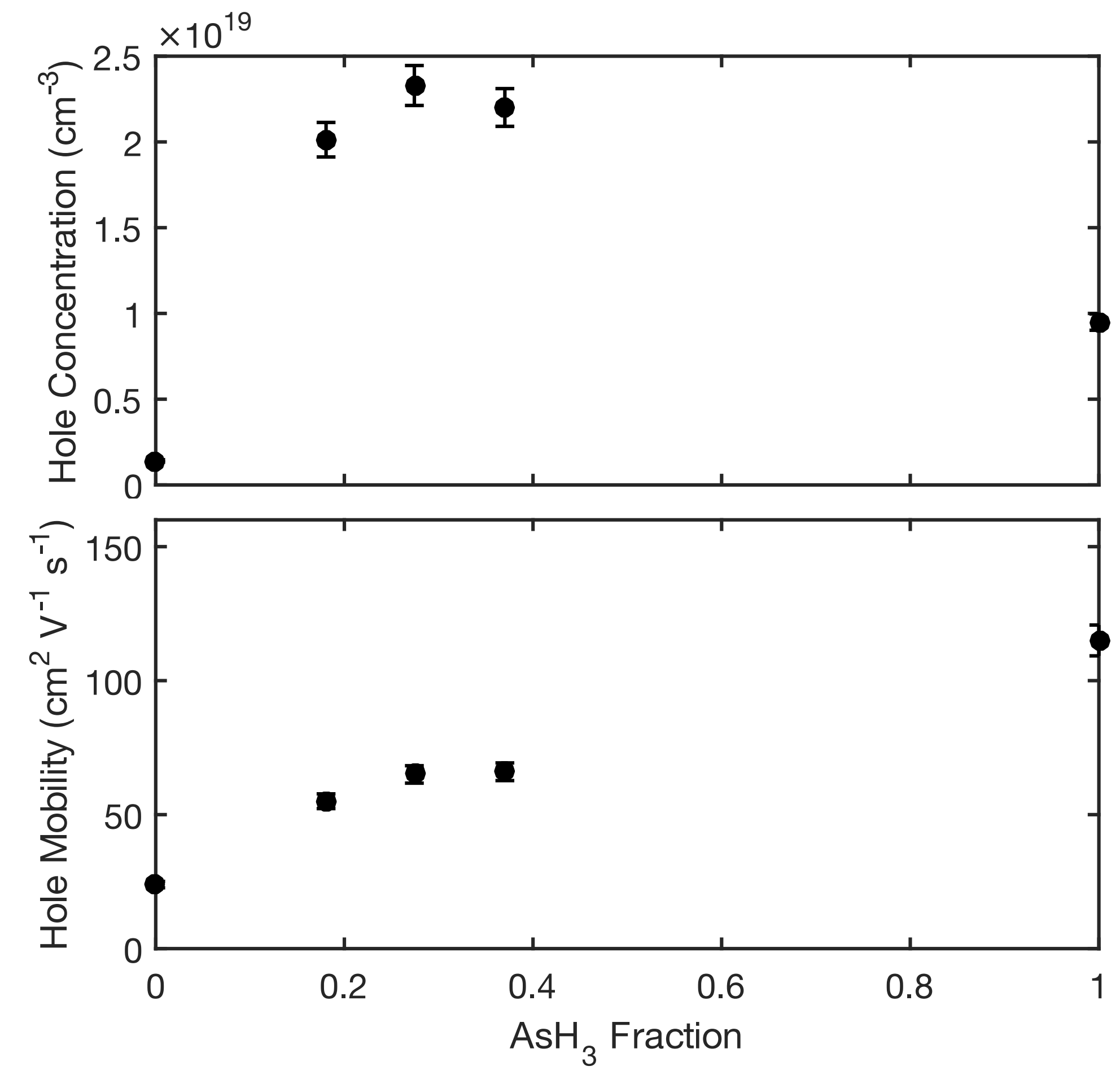

$\mathrm{AsH}_{3}$ Fraction 